\title{
VICENTE RISCO Y LA ESTÉTICA FUTURA. \\ Risco y sus relaciones con la vanguardia. Dos ejemplos de un homenaje a la estética futura.
}

\author{
por \\ EVA VALCÁRCEL
}

\section{En torno a Risco y la vanguardia}

Vicente Risco fue un artista polifacético cuya producción, inscrita en el rexurdemento de la generación Nós, incorpora a la literatura gallega el espíritu de la modernidad. Su perfil intelectual comienza a delinearse en el ambiente universitario compostelano, en donde cursa estudios de Derecho. Otro aspecto de su personalidad, su identificación con los problemas sociales y culturales de Galicia, es producto de las tertulias orensanas de la Comisión de Monumentos, presididas por Marcelo Macías.

La vocación literaria natural del joven Risco se intensifica con las tertulias del café Royalty y con las lecturas indispensables de Mallarmé, Rimbaud, Verlaine y D'Annunzio. Las teorías de Spencer y la filosofía turbadora de Nietzche. En la biblioteca de Primitivo Rodríguez Sanjurjo, poeta modernista y catedrático de Literatura, encuentra información sobre teosofía, ocultismo y mitología oriental.

Risco, ya en sus primeros artículos, publicados desde 1910 en el periódico El Miño, difunde la renovación futurista y durante su estancia en Madrid (1913-1916) su vocación vanguradista se consolidará. En la capital, frecuenta las reuniones literarias y las actividades culturales del Ate-

"CUADERNOS DE ESTUDIOS GALLEGOS", Tomo XXXIX, Fascículo 104, Santiago 1991. 
neo. Ramón Gómez de la Serna registra su participación en las tertulias y los banquetes del Café Pombo ${ }^{1}$.

Cuando regresa a Orense alterna su profesión docente con su labor de creador. En 1917, funda y dirige la revista La Centuria ${ }^{2}$. En el "pronaos" preliminar del primer número, Risco denuncia la tragedia de la "gran guerra presente" y propone "romper el ritmo habitual de la ideas". Describe la posición del hombre moderno, inscrito en el estado del alma del siglo presente. Las siete entregas de la revista orensana transmiten las inquietudes ideológicas de aquellas fechas y difunden textos de Pélédan, Rimbaud, Verlaine, Mallarmé, Oscar Wilde, Chesterton... Gracias a las páginas de esta revista, Risco se convierte en el difusor en Galicia del vanguardismo, con su largo estudio Preludio a toda estética futura ${ }^{3}$.

Los artículos sobre el "nuevo arte literario" se repiten en la revista coruñesa $A$ nosa terra ${ }^{4}$. En 1919 publica los poemas "Esquemaciones fantasistas", de Eugenio Montes y relaciona a Montes con la teoría poética creacionista propugnada por Huidobro:

"Os poemas galegos que hoxe pubricamos de Euxenio Montes están

feitos na escola creacionista, fundada polo poeta chileno Vicente

Huidobro e polos franceses Cendrars e Reverdy. Neles non se

deben buscar as imaxes habituais, coñecidas, á primeira ollada veri-

ficabres; hai que ter en conta -os que non estean ó día nestas cues-

tiós- que eiquí, as imaxes son creadas direutamente polo poeta e non

tomadas do falar corrente, senon impregnadas eiquí por primeira e derradeira vez..." 5 .

Los comentarios de Risco se extienden a la introducción de la renovación poética en Galicia. La revista coruñesa, A nosa terra publicó dos reseñas sobre las vanguardias y su difusión en Cataluña y explicó los principios básicos del manifiesto futurista catalán, Contra els poéts amb minúscula, de Salvat-Papasseit ${ }^{6}$. Poemas de este autor catalán con título

${ }^{1}$ Cfr. La sagrada cripta del Pombo, Trieste, II vol., Madrid, 1981, pp. 536 y 703.

${ }^{2}$ Publicada entre junio de 1917 y julio de 1918. Existe una edición facsimilar -Sotelo Blanco, Barcelona, 1981,-- con presentación a cargo del profesor Francisco Ogando Vázquez.

${ }^{3}$ La Centuria, número: 1, pp. 14-17, 2,17-19; 3,12-16; 5,19-20; 6,16-17 y 7,1921.

4 Organo de las Irmandades da fala, dirigida por Antón Vilar Ponte y publicada en A Coruña entre 1916 y 1936.

${ }^{5}$ A nosa terra, no ${ }^{96}$, A Coruña, 5 de agosto de 1919. Las afirmaciones de Risco hacen referencia a los códigos del creacionismo y a la polémica del poeta chileno con Reverdy.

${ }^{6}$ A nosa terra, $\mathrm{n}^{\mathrm{o}}$ 128,25 de septiembre de 1920 .

"CUADERNOS DE ESTUDIOS GALLEGOS", Tomo XXXIX, Fascículo 104, Santiago 1991. 
de resonancias pictóricas: "Bodegón", "Passeig" y "Linolium", aparecieron también en la revista gallega ${ }^{7}$.

En La Centuria, Risco publicó el ensayo titulado Preludio a toda estética futura, texto revelador para las nuevas orientaciones de la literatura en Galicia. Este texto se anticipa al manifiesto ultraísta encabezado por otro escritor orensano, Xavier Bóveda 8 .

Vicente Risco demuestra conocer los factores culturales que marcan la configuración de una nueva conciencia artística; pero tiene también en cuenta la aportación de las últimas décadas del siglo XIX, del simbolismo y el decadentismo de esta época. La filosofiía del arte por el arte se relaciona con la teorías propuestas en La lámpara maravillosa valleinclanesca; Risco considera que el creador del esperpento fue el fundador en Galicia del "quietismo estético".

Risco explica desde los parámetros de la filosofía contemporánea la teoría estética del "mundo como representación", puntualizando que la verosimilitud" no reside en la imitación de lo real, sino en el poder sugestivo de la creación".

La última parte del Preludio se centra en el análisis de la renovación vanguardista. La creación poética está influída por los poderes daimónicos. El arte presente se inscribe, según Risco, en el reino de la arbitrariedad. El escritor orensano se está refiriendo al nuevo arte difundido en el occidente de Europa, así proclama:

"Hoy es preciso vociferar con Walt Whitman, entonar con Verhaeren cantos augurales".

Al referirse al futurismo, nuestro autor explica con fluidez los códigos estéticos de Marinetti, pero alude también a Boccioni, Severini y al músico Bolilla Pratella. Se detiene en el análisis de la técnica antiartística de los futuristas y establece su propio punto de vista en estos textos:

"...encuentro que hay belleza en una máquina de afeitar; yo veo en la Venus de Milo la media aritmética entre la máquina de afeitar y un ángel de Beato Angélico. Con esto queda definida mi posición.

"Si Edisson dice que es más bella una máquina de afeitar que la Venus de Milo, los futuristas dicen que es más bello un automóvil que la Victoria de Samotracia. Con esto queda definido el futurismo" ${ }^{9}$.

Risco llega a calificar a Marinetti de anticuado al final de la unidad XII de su ensayo, y aboga por un "futurismo nuevo".

\footnotetext{
${ }^{7}$ Id. n⿳o 125,20 agosto, 1920.

${ }^{8}$ Publicado en Grecia, no ${ }^{\circ}$ 128, Sevilla, 15 de marzo de 1919.

${ }^{9}$ La Centuria, no 6, p. 16, Orense, octubre, 1017.
} 
En 1920, con motivo de la exposición de la obra plástica de Castelao, en La Coruña, Risco pronunció una reveladora conferencia: Arte novo, donde analiza las ideas estéticas del cubismo y sus nuevas aportaciones:

"Tratase aínd a de descompoñe-la realidade nos seus elementos esenciais e recompoñe-la seguindo unha norma arbitraria, inventada.

Estos elementos son pra Picasso, e mais pros cubistas ortodoxos -

Xan Gris, Braque, Metzsinger- elementos de forma..." 10.

Una nueva reflexión estética se publica en 1926, en la revista Nós; se trata del breve ensayo titulado "Do futurismo e mais do karma"11, en el que contrapone la realidad presentista a la preformación del futuro, y propone desligarse "do pasotismo e do futurismo" y adoptar la concepción bergsoniana del tiempo y el espacio.

Nós, os inadaptados es un ensayo publicado en 1933; en sus páginas se advierte el perfil del intelectual gallego, "vendido pola vida". El autor da aquí a conocer las lecturas 'que influyen en su posición estética e ideológica, se refiere a Ruskin, Poe, Verlaine, Mallarmé, Ibsen, D`Annunzio, Nietzche, Tagore...

De la influencia de los modelos literarios y filosóficos derivan las bases de su realización como escritor y como intelectual: el individualismo y la libertad interior.

Además de sus artículos teóricos, Vicente Risco publicó en A nosa terra varias de sus composiciones poéticas. Su colaboración poética se inició con tres textos de temas navideños. Uno de estos poemas, que reproducimos, resulta novedoso por su estructura métrica si lo comparamos con la poesía gallega, costumbrista o modernista, de aquellos años:

"¿Cantas luas acesas sobor da nave

na noite de Natal!

A brétema non bota seu alento

en tan craro cristal.

A terra

branca de neve ou de luar

com'unha donceliña de castidá vestida,

hoxe viñérona buscar.

No ceo n'hai estrelas.

Viñeron os anxos a por elas

par'as levar alén.

hoxe choven estrelas

no portal de Belén" ${ }^{12}$.

${ }^{10}$ Conferencia publicada en A nosa terra, nº 114, A Coruña, 20 de marzo de 1920 , pp. 1-6.

${ }^{11}$ Revista Nós, $\mathrm{n}^{\circ}$ 34, 15 de octubre de 1926. pp. 3-5.

${ }^{12}$ A nosa terra, no 73-74, A Coruña, 5 de diciembre de 1918, p.8. 
La estética tradicional se mantiene en las composiciones difundidas en la misma revista coruñesa, "Cantiga pra acompañar co pandeiro", "Balada de mal cristiano" e Interior o Gaston La Touche" 13.

Esta serie de poemas parece contradecir la vinculación del autor con los códigos vanguardistas. Pero Risco escribe textos de vanguardia desde 1920. Su primera composición radicalmente renovadora data de ese año, y se titula "U... ju... juu (poema futurista)"14. También en 1920, esta vez en la revista Grecia, Risco publicó un poema dedicado a Montes, "Bambalinas". Estos dos poemas de 1920 a los que hemos hecho mención ocuparán la segunda parte de este artículo, como dos ejemplos de "estética futura", adhiriéndonos así al sentir del profesor Alonso Montero, quien sostiene que Risco "é un dos primeiros poetas galegos en interesarse polo futurismo... e non sei de ninguén en galego que se adiante nesta modalidade poética" 15 .

\section{U...ju juu..." y "Bambalinas". Notas para la lectura de dos poemas de vanguardia.}

1. "U...Ји јиии... (poema futurista)" (1920).

Terra

Duas áas diagonaladas d'azur baten no mar

Sóbor do Atlántico a diástole imensa da raza

Vapor en todol-os motores do mundo

Añudadol-os nosos nervos á todol-os fíos eléctricos

Terra.

A Cruña fita ás brétemas d'Irlanda

Vigo os raña-ceos de Nova York

GALICIA FOR EVER

CRUÑA

Puntos de tensión máxima da vida

VIGO

Nudo de todol-os fios

enfiando todal-as vilas do mundo

Todal-as airenas a un tempo a sonar

Trés pintados de sol furando a terra.

no cabo de todol-os paralelos

Terra

As flechas das arelas solagadas da Atlántida

${ }^{13}$ A nosa terra, no 112,15 de abril de ${ }^{\circ} 1919$.

${ }^{14}$ Idem., no 113 , A Coruña, 25 de febrero de 1920, p.8

15 "Noticia: Vicente Risco poeta", artículo recopilado en Escritores: desterrados, namorados, desacougados, A Coruña, Ed. do Castro, 1981. pp. 238-243.

"CUADERNOS DE ESTUDIOS GALLEGOS", Tomo XXXIX, Fascículo 104, Santiago 1991. 
Nas nosas espadañas.-

onde repican ô bautizo dos séculos novos

Antenas pra radiografial-os nosos himnos às estrelas

Terra

Folgos de millós de peitos

Mañan

Brinco de todal-as vontades

Estralar de todol-os miolos

Terra

N.S.E.W.

Terra

Chuvia d'estrelas

Alborada

Lostrego

Rayos X.

Profecía

Terra

O ceo rachou d'arriba abaixo

Terra

HIP HIP HIP

HURRA

Xaneiro, 1920.

VICENTE RISCO.

Marinetti, en su Manifiesto técnico de la literatura futurista ${ }^{16}$, expresaba la necesidad de aplicar a la literatura los mecanismos de regulación del progreso, el cual, quedaba esencializado en la idea de forma y la idea de movimiento producido por las alas y las hélices de un avión. Como la hélice en movimiento, la sintaxis futurista ha de manifestarse vertiginosa y circular. La racionalidad sintáctica y lógica será sustituída por los frutos de un azar buscado, el cual participa del sentido de continuidad en la manifestación de la vida. Marinetti quiso propiciar el movimiento de los verbos y los sustantivos, eliminando sus marcas restrictivas, es decir, las formas personales y los adjetivos, frenadores de la visión rítmica y dinámica del tiempo y el espacio ${ }^{17}$. Entramado de sustantivos evocadores, es

${ }^{16}$ En el mes de mayo de 1921 Marinetti publicó el Manifiesto técnico de la literatura futurista. El primer manifiesto del futurismo es de 1909.

${ }^{17}$ El futurismo, que surgió al calor de la revista Poesía de Milán, propugna que la literatura capte los sonidos y los olores y reivindica las aliteraciones, onomatopeyas e hipérboles. la forma será la expresión exterior de un contenido interior, conclusión a la que llegaba Kandinsky al analizar el problema de la forma en un artículo que llevaba esa frase por título y que era publicado en 1912, en Der Blaue Reiter.

"CUADERNOS DE ESTUDIOS GALLEGOS", Tomo XXXIX, Fascículo 104, Santiago 1991. 
decir, entramado de analogías. La vanguardia apoyó incondicionalmente la analogía como principal mecanismo o técnica de creación de significados y de creación de objetos nuevos y a veces imposibles. Las posibilidades de la analogía son innúmeras. La sucesión de imágenes en analogía proporcionan la materia lírica, esto es, el objeto del poema fuera del hombre y su psicología. la grandeza del hombre está en su creación: el progreso, y éste le convierte en minúsculo.

El poema de Vicente Risco que aquí abordaremos, $U . . . j u$ juu... (poema futurista), participa de una parte importante de estas teorías de Marinetti había dado a conocer ocho años atrás. El texto manifiesta su tendencia a la forma móvil y circular: la idea es la de una circularidad abierta, no estancada, móvil necesariamente, totalizadora. La repetición rítmica del sustantivo terra lo confirma. Terra busca la forma y trae la materia y el todo ${ }^{18}$.

El poema se constituye como un canto de fe en el ser humano y una profecía de futuro. El léxico es futurista, constituído por significados de progreso. Podemos hacer referencia para ejemplificar esta idea a la imagen analógica del primer verso: àas diagonaladas d'azur; Las alas diagonalizadas recogen el movimiento físico de una hélice ${ }^{19}$. También diástole recoge el significado de fe en progreso:"Sobor do atlántico a diástole inmensa da raza/vapor de todo-los motores do mundo...". El movimiento calificado como diástole es expansivo, representa el movimiento de la sangre y la dilatación de la duramáter y los senos del cerebro, son características humanas: hombre máquina. Estas características humanas se asimilan a las características del motor de vapor. Se trata de una expansión semejante, de una diástole parecida. A continuación, el hombre nuevo se trasmuta en el engranaje del motor: Los nervios humanos se unen a los hilos eléctricos: "Añudadol-os nosos nervos á todol-os fíos eléctricos". El fluir lírico no olvida el elemento matérico humano, pero lo hace discurrir paralelo a la realidad vital de la máquina creada por él.

La estructura del orbe, sus meridianos y paralelos aúnan y hacen comprensible el universo. Como los puntos en el espacio que una matriz representa, Vigo, Coruña, Irlanda y Nueva York ${ }^{20}$, se encuentran en el eje

${ }^{18}$ Hay que señalar la existencia de una aliteración del fonema /t/ que conduce a una analogía fonética; la repetición del sonido /te/ nos acerca a la representación de un motor. Esta aliteración se produce en todo el texto con mayor o menor intensidad. La repetición del verso "Terra" marca en cierta medida la diferencia de intensidad.

${ }^{19}$ Cfr. González Blanco "El futurismo (una nueva escuela literaria)", Nuestro tiempo, marzo 1910: "Los automóviles y los areroplanos han creado un nuevo tipo estético, que casi casi lleva camino de realizar la tentadora insinuación hecha por Luzbel a nuestros primeros padres en el Paraíso: seréis como dioses...". 
de aquellas primeras dos alas que baten el mar.esas dos alas comprenden y abarcan la tierra toda solidaria: "Brinco de todal-as vontades".

El movimiento descrito en este poema es el de una búsqueda, representa formal y gráficamente un desgarro desde el norte al sur de la corteza celeste en un intento de hermanar voluntades. Pero hay que señalar que esta idea no es una utopía romántica individual de Risco, sino que se hace eco de esa posibilidad de movimiento facilitada por la fe en el progreso que puede comunicar todas las ciudades en las que se albergan de manera ordenada los hombres, todas las sirenas o corazones de los barcos de vapor--nótese la relación: motor de vapor=corazón del hombre; vapor=sangre; sirena=grito humano---- y todos los puntos del orbe----"N.S.E.W."---- 21.

Los conceptos atraen analógicamente otros que comunican el nuevo mundo que ha nacido: el grito tribal de alborozo que constituye el título de la composición: " $U . . . j u$ juи..." pertenece a una pieza musical, de carácter popular, destinada en' su origen a cantar la mañana: la alborada. Alborada ${ }^{22}$ remite a alba, a albor, a mañana y a luz recién nacida ---arte nuevo, mundo nuevo de máquinas, progreso----. Esta idea es recogida de manera más explicita en el verso "mañana" ---mañana=futuro=luz--- y también en el verso: "Profecía". Finalmente todas las ideas se encuentran en dos conceptos: "terra" "todo". Los conceptos se revelan como elementos mediadores que articulan los mensajes de la materia. Risco nos presenta en este poema la ideología del hombre que cree absolutamente en el progreso, como el hombre primitivo creía en la divinidad. El dioshombre ha desplazado a la divinidad como idea de mano inmaterial creadora. El hombre se ha convertido en el Creador que ha hecho las máquinas a "su imagen y semejanza" ---recuérdese vapor=corazón-- ${ }^{23}$.

${ }^{20}$ Es interesante descubrir que la relación entre las ciudades que el poeta nombra no es arbitraria sino que está descrita en términos de paralelos y meridianos: Vigo y Nueva York se encuentran en el mismo paralelo, con una latitud de 42,5 y 40,45 grados Norte, respectivamente; La Coruña y Cork (Irlanda) tienen latitud también Norte de 43,20 y 51,54 grados y coinciden con relación al meridiano, con longitud Oeste de 8,25 y 8,30 grados.

${ }^{21}$ Ramón Gómez de la Serna, firmando como Tristán, en el prólogo a la "Proclama futurista a los españoles" de Marinetti, publicado en la revista Prometeo oㅜ 20, 1910, había escrito: "¡Ala hacia el Norte, ala hacia el Sur, ala hacia el Este, ala hacia el Oeste!.

${ }^{22}$ Alborada procede de albor, luz de alba -a la que canta, poética o musicalmente. Poéticamente la muestra más brillante quizás se halle en la literatura galaico portuguesa, nos referimos al alba o pastorela.

${ }^{23}$ Presentimos aquí al hombre mecánico creado de partes cambiables que no lo liberan finalmente de la muerte.

El motor es una máquina destinada a producir movimiento a expensas de otra fuente de energía, en este caso aprovecha la contracción del corazón y de las arterias para empujar la sangre que contienen y liberar su fuera en la diástole.

"CUADERNOS DE ESTUDIOS GALLEGOS", Tomo XXXIX, Fascículo 104, Santiago 1991. 
Este "poema futurista" constituye un manifiesto de estas nuevas ideas. La estructura de la composición es climática y esencializadora, es decir, el texto tiende a concentrar toda la significación en una sola palabra, aniquilando la sintaxis a medida que se acerca a su fin y, a la vez, a la conclusión de su proceso discursivo. Los cuatro puntos cardinales son enumerados por su inicial y, a continuación, una serie de sustantivos dispuestos gráficamente en forma de escalera condensan esa idea de progreso, idea que está representada por la construcción de sutantivo y su doble, por analogía: "Terra/chuvia de estrelas /alborada/lóstrego/rayos x/profecía".

Una palabra clave repetida rítmicamente sirve, a la vez, para particularizar y universalizar el mensaje del texto; terra, en la primera parte del poema está asociada analógicamente a Galicia como fragmento de esa orbe totalizadora que se revela progresivamente en una segunda parte del texto en la que terra significa mundo, orbe.

\section{2. "Bambalinas" (1920).}

\section{BAMBALINAS}

\section{A mi entrenador Eugenio Montes.}

Los obreros de manos aladas andan tapizando el cielo de sendas enlutadas.

A todos nos ha caído un poco de noche entre las manos.

La luna fue distribuida por igual entre los cabarets y las alcobas.

Y los surtidores son flautas encantadas

Los elefantes que portan al lomo las grandes ciudades han ido con ellas a bañarse en el mar.

Todas las torres son inclinadas

Y se han convertido en telescopios o en cañones.

Por ellas todas las almas han huido hacia la noche.

$\mathrm{Y}$ en el champagne

las sirenas no saben nadar

Se ha visto a los astros bajarse uno a uno del tranvía

Gabán al brazo cansados del largo viaje

Y de la monotonía de danzar en rueda

En los palcos se cierran todos los abanicos como novelas concluidas

Mas en los espejos todavía queda

el último tango y el último fox-trop.

Y la Vía Láctea es el humo de la pipa de aquel noctámbulo de los bulevares colgados del cielo.

$\mathrm{Y}$ así sucesivamente.

hasta que el Altísimo descuelgue todas las bambalinas. 
Risco dedicó este poema a Eugenio Montes, quien había ofrecido a nuestro autor, a su vez, un poema titulado "Atardecer en New York, composición de la que existen ecos en "Bambalinas" 24.

El texto de Risco contiene un doble discurso, la estrategia para introducirnos en él se encuentra en el significado del sustantivo que le da título: Bambalinas. Las bambalinas son, como sabemos, cada una de las tiras de lienzo pintado que cuelga del telar del teatro, abarcando todo el escenario, y en ellas aparece representada la parte superior de lo que la decoración simula. El doble discurso de este texto poético aporta la representación de un crepúsculo natural, en el que los elementos de la naturaleza adquieren características pertenecientes al mundo de la civilización. Por un lado encontramos la continuación que las bambalinas representan, y por otro, lo que en el escenario es representado... El título no es crepúsculo, sino bambalinas; el elemento natural es sustituído por un elemento objetual creado artificialmente por el hombre. lo fabril, lo industrial está presente ya en el primer verso: "Los obreros" traen lo oscuro. Son los aviones de la Primera Guerra mundial que portan la noche, la tragedia. Pero en la naturaleza es también la noche la que llega. La amargura impregna el segundo verso; a todos nos ha caído, como una mancha, la noche en las manos. En la noche, la luna es la luz natural, pero también es la luz eléctrica que ilumina los espectáculos de cabaret y las alcobas. Los efectos de la noche son mágicos y posibilitan que los surtidores canten, el ruido ${ }^{25}$ posee un efecto mágico que facilita la transformación de los surtidores de agua en flautas encantadas. Los elefantes representan la imagen de la solidez, y también, la imagen de la redondez del sol que se

24 Vid. Eva Valcárcel, "La estética activa de los prismas", Cuadernos de Estudios Gallegos, $\mathrm{n}^{\mathrm{o}}$ 103, pp.1 423-442.

El poema de Montes ---publicado en Grecia, en 1919--- contiene también un doble discurso en el nivel de la representación. En el texto se percibe un crepúsculo urbano que enmarca una actitud humana que se confunde con él, como si se tratase de una relación entre decorado y comedia. Las imágenes de los dos poetas evocan sensaciones muy similares como podemos comprobar si comparamos algunos versos:

"Los rascacielos, inclinados, elevan sus plegarias a las nubes " (Montes)--- "Todas las torres son torrres inclinadas..." (Risco).

"El sol está detenido en un vaso en la mesa de la terraza de un bar ---(M)---"Y la Vía Láctea es el humo de la pipa de aquél noctámbulo..."(R)----

¿¿Dónde está la concha del apuntador? (M)----"En los palcos se cierran todos los abanicos ..."(R)__ alusión a la representación

${ }^{25}$ Para conseguir recrear la obsesión lírica por la materia que los futuristas consideraban el objeto de máxima elaboración del arte, introdujeron en la literatura tres elementos que hasta entonces no habían sido tenidos en cuenta: el ruido, que manifiesta el dinamismo de los objetos, el peso, que expresa la facultad o imposibilidad del vuelo, y el olor, que representa la facultad de esparcimiento de la materia. 
entierra en el mar en el momento del crepúsculo. El elefante, según la tradición, da a todos los que lo invocan lo que desean. Es símbolo de estabilidad pero no de pesadez, simboliza lo eterno, lo inmutable. El elefante es un animal cósmico porque posee en sí mismo la estructura del cosmos: cuatro pilares sujetando una esfera. Por el efecto de la perspectiva y de la sombra del crepúsculo, las torres que son rectas, parecen inclinadas, semejan algo que no son, creadas y dominadas por el progreso, aparentan algo bien dispar: telescopios para ver más lejos ---idea de futuro, de

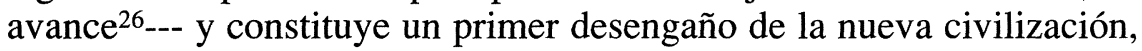
cuando semejan cañones ---recuerdo de la guerra---. Las torres cobijan a los habitantes del escenario teatral que es una ciudad moderna. La torre por excelencia es la Torre de Babel que procedía del deseo de aproximación a Dios para canalizar su sabiduría hacia la tierra, y finalmente, se convierte en lo contrario, en la obra del orgullo humano, en la ciudad que se yergue contra Dios. Este miedo a la decepción se respira en el poema.

El elemento natural y mágico, las sirenas ya no pueden nadar en el champán, ellas se han refugiado en los cabarets. Las sirenas seducen a los navegantes por la belleza de su canto; simbolizan la autodestrucción, recordemos la leyenda de Ulises, quien tuvo que hacerse atar al mástil de su navío para poder resistir su llamada.

La contraposición entre lo natural y lo creado aparece otra vez cuando el cielo se cubre de estrellas en plena noche, pero ellas llegan cansadas y aburridas, lamentando lo rutinario cotidiano; llegan a un lugar en donde hay muchas luces, las de la civilización. Las estrellas aburridas son también los hombres y mujeres de la ciudad que llegan, con la noche en las manos, a casa. Es muy tarde y los espectáculos del crepúsculo y de la jornada de trabajo en la ciudad se acaban. Una pequeña porción de orbe, nuestra galaxia, la Vía Láctea, reconoce su insignificancia frente a la inmensidad del orbe, semeja una burbuja en el cigarrillo de los noctámbulos. Pequeñez de lo natural frente a lo creado por el hombre.

El poema está construído con arreglo a una progresión hacia el desenlace del crepúsculo y de la jornada. Desde la tarde hasta la madrugada. En el acercamiento semántico al poema podemos comprobarlo:

\footnotetext{
${ }^{26}$ La idea de sucesión y de progresión está subrayada en el poema por medio de la introducción rítmica de unidades versales que poseen una relación de copulatividad:

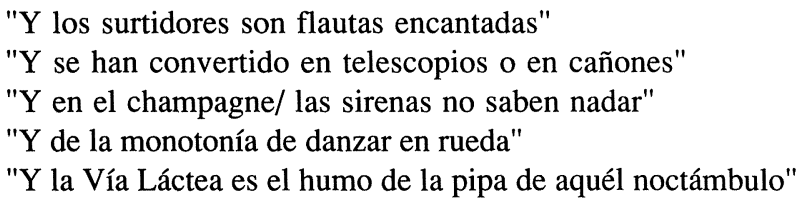


"las sendas enlutadas"|"las sombras"|"las torres"|"el cabaret". Hemos ido adentrándonos, a medida que anochecía fuera, allí donde había más luz, hemos ido buscando la luz que se hallaba en el lugar más concreto, cerrado y teatral, en el universo urbano más pequeño, el cabaret. La idea que predomina en el poema es la de movimiento cotidiano, monótono, "en rueda"; no es la velocidad de vértigo de las hélices. La rueda es el símbolo privilegiado del desplazamiento y contiene la perfección sugerida por el círculo, pero con una cierta violencia de imperfección, porque ella significa el mundo del futuro, de la creación continua. Nicolás de Cusa decía que el mundo era una rueda en una rueda, una esfera dentro de una esfera, dando así la idea de movimiento perpetuo e inacabamiento esencial $^{27}$.

Existe también una idea meláncólica de duda, de acabamiento, que se enfrenta a la magia de la noche: por un lado, la noche cae entre nuestras manos como mancha, y por otro, convierte a los simples surtidores en mágicas flautas. La flauta fue inventada por Pan, su sonido representa la música celeste. Orfeo fué vencedor con su flauta de las fuerzas de la Naturaleza como Jesús de Satán, según los autores cristianos. Nuevamente estamos ante un sentido dual y ante la presencia del elemento mágico, esencial para la representación.

${ }^{27}$ Cfr. Nota 26.

"CUADERNOS DE ESTUDIOS GALLEGOS", Tomo XXXIX, Fascículo 104, Santiago 1991. 